\title{
Traces of the Second Demographic Transition in Four Selected Countries in Central and Eastern Europe: Union Formation as a Demographic Manifestation
}

\author{
Jan M. Hoem · Dora Kostova · Aiva Jasilioniene • \\ Cornelia Mureşan
}

Received: 4 April 2008/ Accepted: 12 December 2008/Published online: 10 February 2009

(C) The Author(s) 2009. This article is published with open access at Springerlink.com

\begin{abstract}
Using data from the first round of the national Gender and Generations Surveys of Russia, Romania, and Bulgaria, and from a similar survey of Hungary, which were all collected in recent years, we study rates of entry into marital and non-marital unions. We have used elements from the narrative of the Second Demographic Transition (SDT) as a vehicle to give our analysis of the data from the four countries some coherence, and find what can be traces of the SDT in these countries. The details vary by country; in particular, latter-day developments in union formation patterns did not start at the same time in all the countries, but in our assessment it began everywhere before communism fell, that is, before the societal transition to a market economy got underway in 1990.
\end{abstract}

Keywords Marriage - Cohabitation · First union ·

Joint analysis of competing risks · Second Demographic Transition ·

Central and Eastern Europe $\cdot$ Russia $\cdot$ Romania $\cdot$ Hungary $\cdot$ Bulgaria

Résumé A partir des données de la première vague d'enquêtes du projet Générations et Genre en Russie, en Roumanie et en Bulgarie, et à partir d'une enquête comparable en Hongrie, toutes conduites récemment, cette étude s'intéresse aux taux d'entrée en union conjugale et non-conjugale. Nous avons utilisé des éléments du cadre descriptif de la seconde transition démographique comme grille d'analyse pour donner une cohérence aux données des quatre pays, et pour y explorer les traces de ce modèle de transition. Chaque pays a un contexte à part; en particulier, les évolutions récentes dans les modalités de formation des unions ont des

\footnotetext{
J. M. Hoem $(\bowtie) \cdot$ D. Kostova · A. Jasilioniene

Max Planck Institute for Demographic Research, Konrad-Zuse-Str. 1, Rostock 18057, Germany

e-mail: Hoem@demogr.mpg.de

C. Mureşan

University Babeş-Bolyai, Bd. 21 Decembrie nr. 128, 400604 Cluj-Napoca, Romania
} 
calendriers variables, mais d'après notre étude le processus a commencé partout avant la chute du communisme, et donc avant la transition à l'économie de marché dans les années 90 .

Mots-clés Mariage - Cohabitation · Première union ·

Analyse conjointe des risques compétitifs - Seconde transition démographique .

Europe centrale et de l'est · Russie, Roumanie, Hongrie, Bulgarie

\section{Introduction}

In this article, we study trends in family-formation behavior since 1960 in the countries that used to be called the Eastern Bloc. In this connection, the account of the Second Demographic Transition (SDT) is very attractive, both as a generalized summarizing description and because of its underlying theory of value change in the direction of increasing tolerance in family matters and of women's increasing autonomy (Lesthaeghe and van de Kaa 1986; Lesthaeghe and Surkyn 2002; for a recent, independent assessment, see Sobotka 2008). The SDT account consists of a narrative of changes in demographic behavior and of an explanation for those changes. The changes on which the narrative focuses are a decline in marriage formation, an increase in non-marital cohabitation, a general decrease in fertility (particularly at higher birth orders) but an increase in non-marital childbearing, an increase in union disruption, and a postponement of marriage and childbearing. Briefly stated, the explanation given is that these developments are caused by ideational changes regarding family life and childbearing, i.e., changes in norms, values, beliefs, and attitudes, sometimes operating in tandem with political, economic, and social changes.

There is ample evidence of most of the demographic developments in the SDT narrative all over Europe, particularly concerning fertility trends; see for instance Frejka et al. (2008). There is also already quite some literature on recent changes in union-formation behavior in Central and Eastern Europe and on their interpretation (Carlson and Klinger 1987; Lesthaeghe and Surkyn 2002; Aassve et al. 2004; Spéder 2004 and 2005, Zakharov 2005, Gerber and Berman 2005; Koytcheva 2006, Thornton and Philipov 2007; Kostova 2007, Muresan (2007a, b), and Bradatan and Kulcsar 2008). ${ }^{1}$ Too little attention has been given so far to the finer structure of the trends in union-formation risks in the region, however, which is surprising, given that ideational change must be a force behind the growth in non-marital cohabitation and therefore a prime indicator of the very explanation given for the SDT. In this article, we focus therefore on non-marital cohabitation as a competitor to conventional marriage. Our account is for Bulgaria, Romania, Russia, and Hungary, for we are fortunate in having early access to the data from the first round of the Gender and Generations Surveys (GGS) in the first three of these countries and to their close counterpart for Hungary. ${ }^{2}$ All the surveys have used a random sample of

\footnotetext{
1 A Russian-reading colleague has also made us aware of Maleva and Sinyavskaya (2007).

${ }^{2}$ For a description of the GGS program, see Vikat et al. (2007); for a description of the Hungarian survey, see Spéder (2001).
} 
Table 1 Person-years of exposure since 1960

\begin{tabular}{lllll}
\hline & \multicolumn{2}{l}{ Total person-years of exposure } & \multirow{2}{*}{ Year of data collection } \\
\cline { 2 - 4 } & As childless, not pregnant & As childless, pregnant & At parity $\geq 1$ & \\
\hline Russia & 35,161 & 373 & 3,865 & 2004 \\
Bulgaria & 40,057 & 360 & 1,989 & 2004 \\
Romania & 33,931 & 290 & 1,416 & 2005 \\
Hungary & 49,747 & 455 & 951 & $2001^{1}$ \\
\hline
\end{tabular}

Note ${ }^{1}$ The first wave of the Hungarian GGS (originally called "Turning points of the life-course") was conducted in November 2001 through January 2002, but we do not use data collected in 2002 in our study Source Our own calculations based on GGS data

women and men of all relevant ages. In this present study, we use the data for women only; for sample sizes (in terms of years of exposure) see Table 1.

We started this investigation in a descriptive mood and without any strong preconceived ideas or hypotheses about union-entry trends, but with a series of open questions. We were curious to see to what extent the fall of communism around 1990 might have given a particular impetus to developments in union formation across the four countries, and what commonalities we could find in the patterns of such developments. The single-country background and previous literature has been described succinctly for Russia and Bulgaria by Philipov and Jasilioniene (2007), ${ }^{3}$ for Romania by Muresan (2007a, b), ${ }^{4}$ and for Hungary by Spéder (2005). The three former authors have provided extensive survival tables for Russia, Bulgaria, and Romania in the spirit of Andersson and Philipov (2002), who gave such tables for Hungary and fifteen other European countries for an earlier period. Following Carlson and Klinger (1987); Spéder (2004, 2005) maintained that post-divorce nonmarital cohabitation has old roots in Hungary and that consensual first unions gained considerable ground in that country well before the regime change. We focus on first unions and find similar patterns also for Russia, Romania, and Bulgaria.

Table 2 contains some highlights for the three GGS countries for which period survival tables are available, ${ }^{5}$ and we see that there was considerable cohabitation already around the late 1980s and that in Bulgaria and Russia, it had outflanked direct marriage at least by the early 21 st century. According to this table, Romania seems to be in a different category, where marriage had held up much better than in Bulgaria and Russia. Statistics like those of Table 2 have been derived from straightforward occurrence/exposure rates, with no standardization nor any other attempt at hedging against compositional effects; so, we started out wondering to what extent the considerable differences between the countries would hold up to closer scrutiny.

\footnotetext{
${ }^{3}$ See also Zakharov (2008) and Koytcheva \& Philipov (2008).

4 See also Mureşan et al. (2008).

5 We have not found comparable information for Hungary, also because Spéder (2005 etc.) has worked consistently with birth cohorts rather than with calendar periods.
} 
Table 2 Entry into marital and non-marital unions as competing events in Bulgaria, Romania, and Russia. Period survival-table estimates. Percent ever entered by age 35 . Women

\begin{tabular}{|c|c|c|c|c|c|c|}
\hline \multirow[t]{2}{*}{ Period } & \multicolumn{2}{|c|}{ Bulgaria $^{a}$} & \multicolumn{2}{|c|}{ Russia $^{a}$} & \multicolumn{2}{|c|}{ Romania $^{\mathrm{b}}$} \\
\hline & \multicolumn{2}{|c|}{$\begin{array}{l}\text { Ever entered into } \\
\text { cohabitation marriage }\end{array}$} & \multicolumn{2}{|c|}{$\begin{array}{l}\text { Ever entered into } \\
\text { cohabitation marriage }\end{array}$} & \multicolumn{2}{|c|}{$\begin{array}{l}\text { Ever entered into } \\
\text { cohabitation marriage }\end{array}$} \\
\hline 1985-1989 & 54 & 37 & 34 & 62 & $20^{\mathrm{c}}$ & $76^{\mathrm{c}}$ \\
\hline 1990-1994 & 60 & 32 & 46 & 50 & & \\
\hline 1999-2003 & 63 & 14 & 62 & 33 & $35^{\mathrm{d}}$ & $56^{\mathrm{d}}$ \\
\hline
\end{tabular}

\footnotetext{
a Source Philipov and Jasilioniene (2007), Table A8

b Source Muresan (2007b), Tables 5.5 and 5.6

c 1980-1989

d 1996-2005
}

\section{Method and Covariates}

In demography, one of the ways to handle compositional effects is by using standardization, and we have applied this method in the form of an unusual variant of intensity regression where entry into marriage and into a non-marital union are studied jointly as competing risks in a manner that permits direct comparison between the two types of union formation in each of the four countries. ${ }^{6}$ This procedure has been described most fully by Hoem and Kostova (2008), to whom we refer for mathematical aspects of the approach we use. (We give some further discussion of such items in an appendix to this article.) They also gave a first application to the Bulgarian GGS data already. This article can be regarded as a further elaboration of the Bulgarian data and an extension to the three other countries for which we also have data.

Based on data in a monthly format for the years since 1960, we have used proportional-hazards event-history analysis with a piecewise constant baseline intensity to reflect the impact of a woman's age, formally using the type of union formed as a fixed covariate in addition to the other fixed and time-varying covariates available to us (the determinants). Among the determinants we have included a time-varying covariate that we call pregnancy-and-parity status. It provides a differentiation between (i) non-pregnant childless women (ii) pregnant childless women, ${ }^{7}$ and (iii) mothers, i.e., women at parities 1 and above. The first of these

\footnotetext{
${ }^{6}$ We also sometimes call the type of union formed (marital or non-marital) a decrement, in line with actuarial terminology, which focuses on the mode of exit from the non-partnered status.

${ }^{7}$ In line with much demographic practice, we have counted a woman as knowingly pregnant during the seven calendar months just before the month in which she gave birth. We have used seven instead of nine months because initially we thought that few women can be sure they are pregnant and also able to enter a union during the first one or two months of a pregnancy. At the time when we complete our last revision, we are no longer sure that this argument is valid, because Kostova (2008) recently discovered that at least in Bulgaria and Russia union-entry behavior changes visibly already nine months before the first birth recorded. She also found that the choice between nine and seven months is unimportant for the analysis of union entry, however, so we have kept our alternative of seven months so as to avoid having to make recalculations to little effect.
} 
three groups overwhelmingly dominates the exposures to the risk of first-union formation (Table 1) and we report most of our results for this group alone. Since our focus is on the changing trends in union formation, we display the interaction between calendar time and union type in our descriptions below, and let the other available covariates appear as control variables. These are most importantly (selfreported) ethnicity, but also a number of covariates that are intended to reflect other aspects of the respondent's background, namely whether she grew up in an urban or rural region, whether she lived with both parents at age 15, her number of siblings, her own educational attainment, and the educational attainments of her mother and father. ${ }^{8}$ These are standard covariates readily available in our data, except the respondent's own educational attainment. We would have used it more extensively if we had had enough information to make it a genuine time-varying covariate, but the data only contain the attainment made by the time of data collection plus the time at which the respondent had reached this level of education (according to her own report), so we have had to impute a non-fixed covariate using a method developed by Hoem and Kreyenfeld (2006). Since this is not the real thing, we do not report the outcome here, nor do we report the risk patterns for our other control variables, mainly in order not to detract attention from our main focus on unionentry trends, but also because they do not contain any really notable surprises, particularly since Bradatan and Kulcsar (2008) went this way before us. Among the findings that we do report is a strong drop in the marriage-formation risk in all the four countries and a counterpart increase in the risk of entry into non-marital unions, though surprisingly in Bulgaria (and possibly Hungary) this increase turned into a drop at the beginning of the 2000s. ${ }^{9}$ As one of our referees has pointed out, this may just be a sign of accelerated postponement of entry into a first union, which would be another typical trait of the SDT.

To give a feeling for the size order of the relative union-formation risks in our four data sets in the twilight years of state communism, we attach Table 3, where for each country we display the (two-way) empirical interactions between the type of union formation (marital and non-marital) on the one hand and pregnancy-and-parity status on the other. The estimates have been produced by an intensity regression where age and calendar time appear formally as (timevarying) control variables not involved in any interactions, so the figures represent a kind of average over active childbearing ages and over the forty-odd years since 1960 .

The general pattern is that as long as a woman was childless and not pregnant, the risk of entry into a non-marital union most often was low by comparison to the risk of marriage formation. Bulgaria constitutes an exception, in that entry into cohabitation was the higher. (We return to this deviation below. Note that our method allows for a direct comparison of the union-formation risks across the two types of unions in each country.) Not surprisingly, the union-formation intensities

\footnotetext{
8 Some of these covariates have not been available for Hungary. For Romania we did not include the parents' educational attainments because of data-quality problems.

9 For the same feature see also Hoem and Kostova 2008, Fig. 3. The calculations in this article and in theirs extend to 2004. In work that has not been published yet, Kostova has found that the drop continued through 2007.
} 
Table 3 Relative risk of first-union formation by parity-and-pregnancy status, for each type of union. Our selected countries, 1960-ca. 2004

\begin{tabular}{llll}
\hline & Childless, not pregnant & Childless, pregnant & Parity $\geq 1$ (mother) \\
\hline Russia 1960-2004 & & & \\
Cohabitation & 0.50 & 2.34 & 0.48 \\
Marriage (direct) & 1 & 8.40 & 0.42 \\
Bulgaria 1960-2004 & & & \\
Cohabitation & 1.31 & 11.69 & 0.64 \\
Marriage (direct) & 1 & 17.07 & 0.47 \\
Romania 1960-2005 & & & 0.16 \\
Cohabitation & 0.24 & 1.70 & 0.73 \\
Marriage (direct) & 1 & 8.47 & 0.50 \\
Hungary 1960-2001 & & & 1.25 \\
Cohabitation & 0.32 & 1.36 & 17.69 \\
Marriage (direct) & 1 & 1.69 & \\
\hline
\end{tabular}

Note Standardized with respect to age, ethnicity, calendar period, character of region where respondent grew up (urban/rural), whether respondent lived with both parents at age 15, number of siblings, own educational attainment, and mother's and father's educational attainments. Some of these covariates have not been available for Hungary. For Romania the parents' educational attainments were not included because of data quality problems

Source Our own calculations based on GGS data

increased strongly if the woman became pregnant, and the increase was particularly strong for marriage formation. If she did not form a union before she had her (first) child, then the entry intensities largely went back to the size order they had before she became pregnant, or even to something smaller. It is as if the arrival of the first child is some kind of watershed, after which the woman was less attractive as a partner, or alternatively that the remaining women were less attracted by partnership. Only in Hungary, mothers still ran a (somewhat) higher risk of entry into a union, especially a marital union, than before they became pregnant.

\section{Trends Over the Years Since 1960}

To get closer to the changing dynamics of union formation, we report the trends in (standardized) entry rates since 1960 in Fig. 1, computed separately for each of the four countries. These are relative risks of entry into cohabitation and into marriage for childless non-pregnant women ${ }^{10}$ in a two-way interaction between calendar period and decrement type, standardized for the control variables listed above. The

\footnotetext{
${ }^{10}$ Because of the exposure dominance of the non-pregnant childless women, the interaction would not have been much different even if we had disregarded pregnancy-and-parity status.
} 

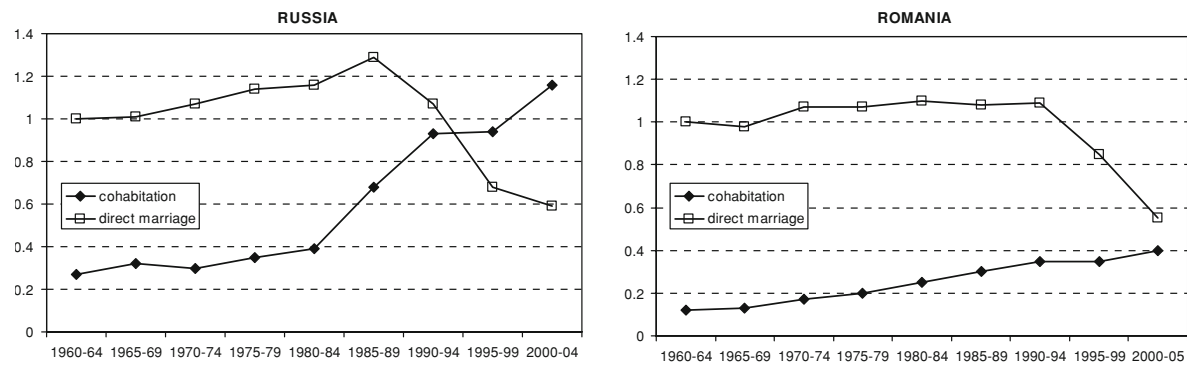

BULGARIA
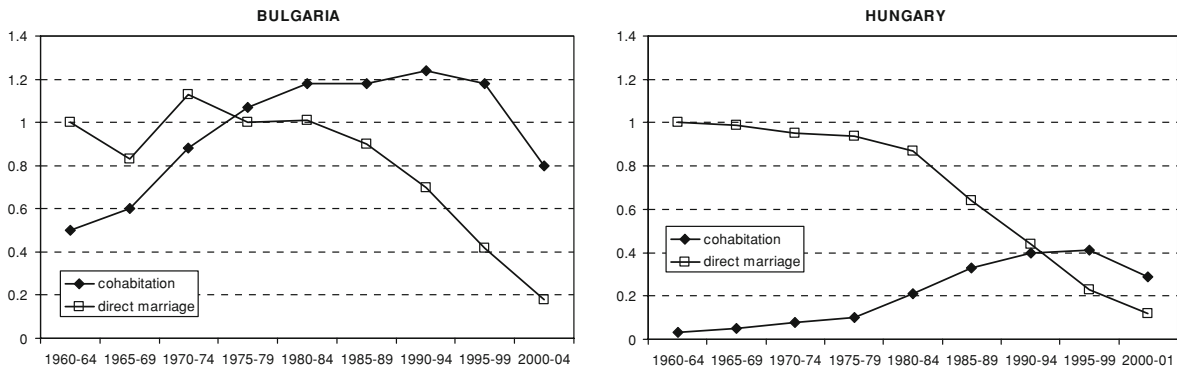

Fig. 1 Trends in the rates of union formation, by type of union. Non-pregnant childless women in Russia, Romania, Bulgaria, and Hungary, since 1960. Rates relative to that of direct marriage during 1960-1964, separately for each country. Source Our own calculations based on GGS data

basis of comparison is the country-specific risk of entry into a marital union for childless non-pregnant women in 1960-1964. ${ }^{11,12}$

The following patterns strike the eye:

In Bulgaria and Hungary, marriage risks have decreased over time ever since the early 1980s (roughly); in Russia they have decreased strongly since half a decade later, and in Romania since another half a decade later again. In all the countries, the risks of entry into non-marital unions have increased ever since the 1960s, much as one would expect from descriptions of the SDT. ${ }^{13}$ Taken together, these manifestations started well before the fall of communism, particularly for entry into consensual unions. Developments of this nature have been noted earlier by Gerber and Berman (2005) and by Spéder (2004, 2005).

\footnotetext{
11 The diagram for Bulgaria deviates somewhat from the corresponding diagram in the article by Hoem and Kostova (2008) because their computations were for the cohorts born in 1955 and later while the present diagram is for all the cohorts in our data, as it is for all the countries in our study.

12 We have further experimented with an intensity model that also contains (i) an interaction between the type of union formation and age attained as well as (ii) an interaction between union type and the control covariates. We have relegated an account of the mathematics involved to our appendix, which also contains a discussion of the items plotted in Fig. 1 and the subsequent Fig. 2 in terms of relative risks.

${ }^{13}$ We are struck by the rather low rates of entry into a consensual union in Hungary (as compared to direct entry into marriage); nevertheless this country seems to conform to the SDT narrative reasonably well. Since about the year 2000 cohabitation has been the dominant choice of first union formation in this country (see similar findings by Spéder 2006 and Spéder and Kamarás 2008, Figs. 16 and 17), and the low total level of entry into a first union after 1995 fits with SDT arguments about a longer period of single living and delayed union formation in general.
} 

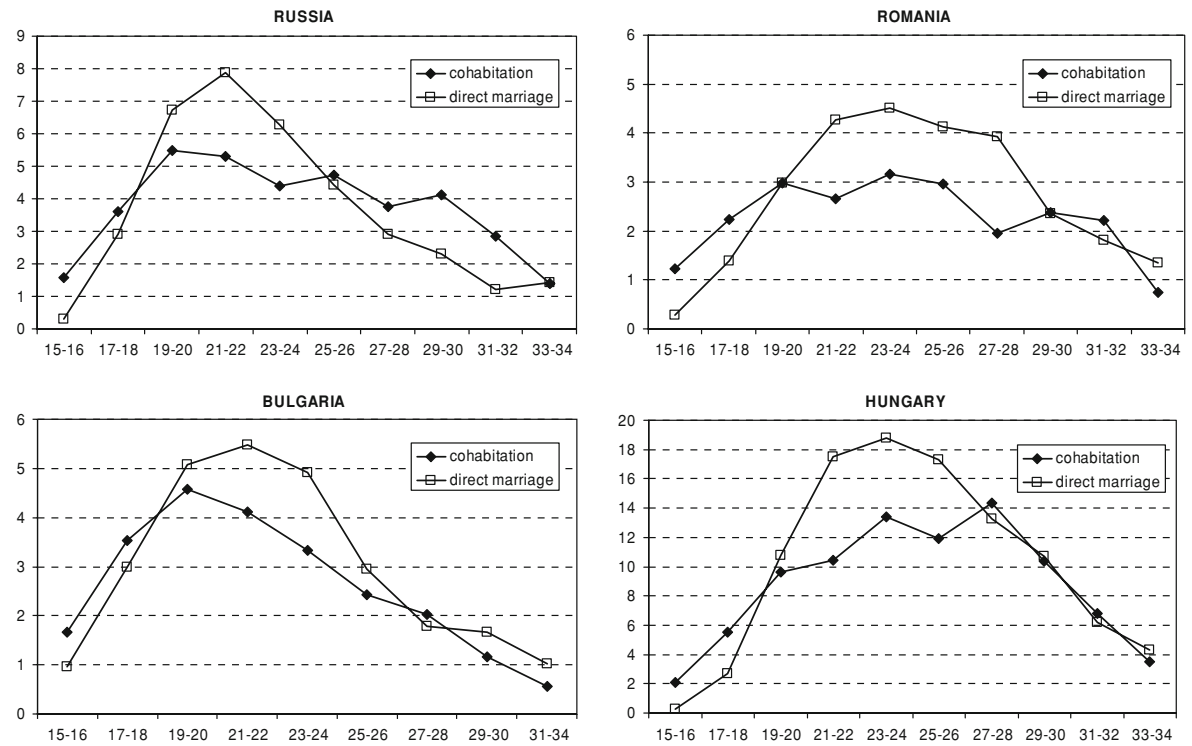

Fig. 2 Age profiles of entry risks of union formation, by type of union. Non-pregnant childless women in Russia, Romania, Bulgaria, and Hungary, 1960-ca. 2004. Absolute risks per 1,000 person-months. Source Our own calculations based on GGS data

Bulgaria seems to be having a case of its own. As we just said, the marriage risk has fallen since the early 1980s, but the entry risk for cohabitation stabilized during the 1980s and 1990s. If anything, it dropped after the turn of the century. This looks like a deviation from (standard) patterns in the SDT, though one should note that the cohabitational entry risks continued to increase relative to the marriage risks throughout the whole period of our observation. ${ }^{14,15}$

Romania is another exception from the general trend in the risks of entry into cohabitation, relative to that of marriage formation. Even if the process of first union formation largely follows the trends observed in the other three countries, marriage was the dominating type of first union throughout the entire period of observation.

If we add an interaction between age attained and decrement (union type) in the intensity regression that produces the standardized risk trends mentioned above, we get age profiles for the two entry risks as an extra bonus (Fig. 2). (For the mathematics, see our appendix once more.) We had expected entry into cohabitation to be shifted toward younger ages than the age profile for marriage formation, much

\footnotetext{
14 The entry risk for cohabitation relative to the corresponding risk of marriage formation in Bulgaria rose steadily as follows:

1960-64 1965-69 1970-74 1975-79 1980-84 1985-89 1990-94 1995-99 2000-04

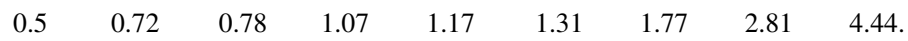

15 There is a hint of a drop in the entry risk for cohabitation between the periods 1995-1999 and 20002001 in Hungary as well, but we do not pay much attention to this since the latter period is only two years long in Hungary as against five years for other periods and countries. Random variation may therefore play a greater role than otherwise at the tail end of the curve for Hungary.
} 
as in the diagram for Bulgaria, but the diagrams for Russia, Hungary and Romania show how incorrect such a preconception could be.

\section{Shifting Age Profiles}

The findings presented in Section 3 provide a neat and compact description of entry trends in the four countries, based on a standardization technique of a type that is ubiquitous in demography. ${ }^{16}$ Standardization is known to summarize risk trends and differentials well under wide conditions, and to be robust against mild deviations from those conditions.

One of the conditions that we have not addressed above is the assumption of a stable age profile in the risks, i.e., we have behaved as if each of the two piecewise constant baseline hazards (one for each decrement) were the same for all calendar periods in the analysis. This may have simplified matters unduly; after all, many authors document to their satisfaction that there has been a delay in union formation, so marriage and perhaps entry into cohabitation occur progressively later in life as calendar time increases. One question is, therefore, how robust the results above are against what may be a misspecification.

To check on this question, we have estimated the hazard parameters once more, but now with a three-way interaction between age, period, and decrement. ${ }^{17}$ The outcome is given in Fig. 3, where to avoid needless complication, we have temporarily used five-year age groups and have concentrated on the years between 1980 and the survey date. ${ }^{18}$ For each country, we have plotted the age profiles of the rates of union formation for each period $k$, and we get the following graphical patterns, which can serve as a simple optical goodness-of-fit test of our basic specification.

For Hungary the entry risk for marriage formation has indeed shifted steadily toward higher ages; for entry into cohabitation they seem to have shifted somewhat in the opposite direction. For Romania we also see a bit of a shift toward later ages in the risk of entry into marriage, while in Bulgaria we can see a similar shift in the risk of entry into non-marital cohabitation. With some good will, one can even discern some tendency for the profile to shift a little toward younger ages in the risk diagrams for Russia. All in all, perhaps there is only a mild deviation from the requirement of a stable age profile in Bulgaria, Russia, and Romania.

By way of conclusion, to get a realistic representation it looks as if we may be able to make do with our original intensity specification for Russia, Romania, and Bulgaria, but not necessarily for Hungary. For the latter country, we have therefore

\footnotetext{
16 Using hazard regression in our situation is just a practical manner of applying indirect standardization.

${ }^{17}$ In the mathematical terms of our appendix, we specify $\mu=A C D+B$ and see whether we can actually decompose $A C D$ as $A D+C D$ in our data. In a different formulation, this means that instead of a simple model $\mu_{i j k h}=a_{i h} b_{j} c_{k h}$ we fit $\mu=a_{i k h} b_{j}$ and see how realistic it is to suppose that $a_{i k h}$ can be split as $a_{i k h}=a_{i h} c_{k h}$ (if we allow ourselves some lenience in mathematical representation).

18 The use of five-year groups instead of the shorter age groups is intended to avoid an overly strong impact of random variation. An extension back to 1960 and the use of shorter age groups essentially give the same picture (not documented here). The results remain standardized with respect to the control variables in our analysis.
} 

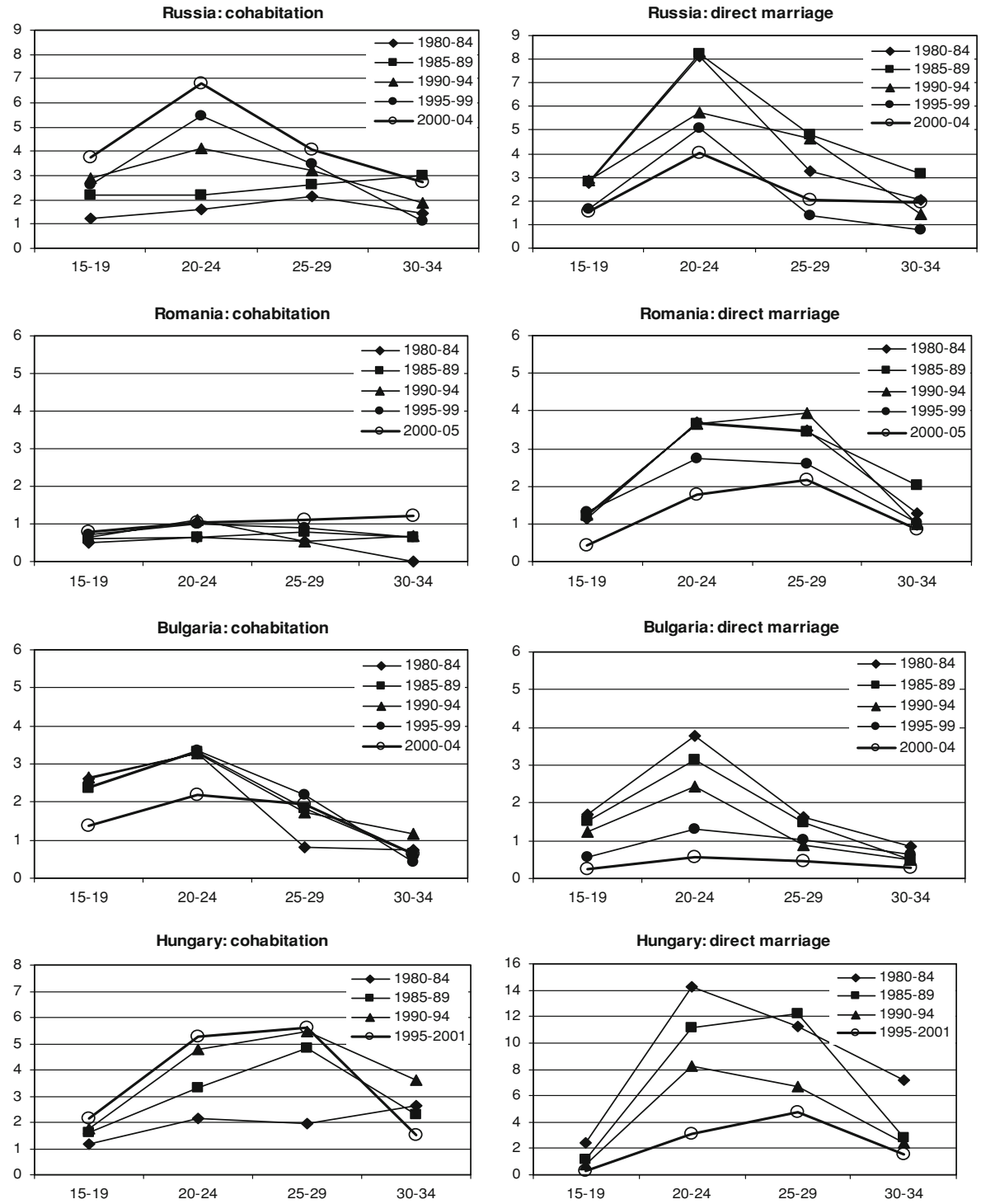

Fig. 3 Age profiles of entry risks of union formation, by type of union and period. Non-pregnant childless women in Russia, Romania, Bulgaria, and Hungary, 1980-ca. 2004. Absolute risks per 1,000 person-months. Source Our own calculations based on GGS data

tried the specification with a three-way interaction between age, period, and decrement once more, but now with our finer age specification and with periods back to 1960. The result is that for each age group we can essentially draw a diagram like that of the corresponding panel in Fig. 1 (details available from the first author). In our view, therefore, the whole story of the entry trends in Hungary 
BULGARIA

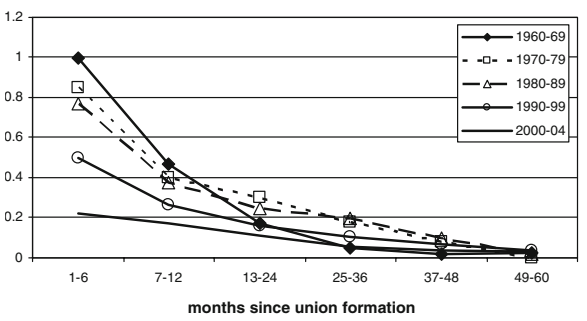

HUNGARY

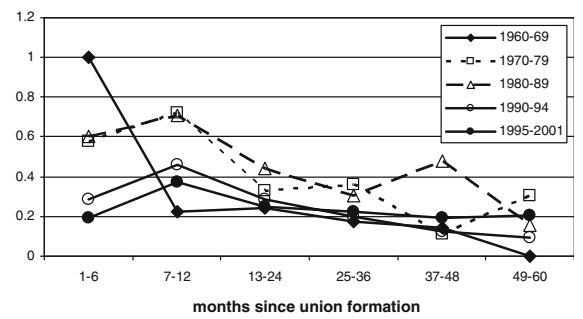

Fig. 4 Relative rates of conversion of cohabitation into marriage, by time since entry into cohabitation for each calendar period, women in Bulgaria and Hungary, 1960-ca. 2004. Rates relative to a conversion during the first 6 months in the period 1960-1969. Source Our own calculations based on GGS data

since the 1960s is adequately represented in Fig. 1, in any case. Except for details, we draw the same conclusion concerning the intensity age profiles in Fig. 2.

\section{Conversion of Non-Marital into Marital Unions}

As we mentioned toward the end of Section 3, we have found that lately the risk of entry into cohabitation has dropped somewhat in Bulgaria. To see whether this means that Bulgarian women have given up on the SDT, at least as far as union formation is concerned, it pays to introduce an additional dimension, namely, the conversion of non-marital unions into marriages. One take on this is our Fig. 4a, which is similar to a corresponding figure presented by Hoem and Kostova (2008, Fig. 4), but which is now constructed in a way that covers the whole period and the entire population of this study. In Fig. 5 the same data are seen from a different angle, but it tells the same story, namely, that the SDT remains in progress in Bulgaria. Here is some further background information.

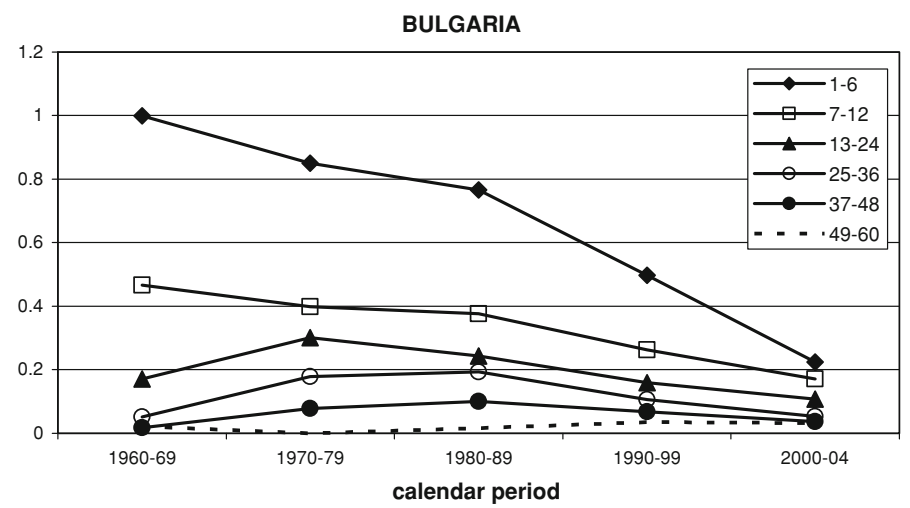

Fig. 5 Relative rates of conversion of cohabitation into marriage, by calendar period for each duration since entry into cohabitation, Bulgarian women, 1960-2004. Rates relative to a conversion during the first 6 months in the period 1960-1969. Source Our own calculations based on GGS data 
Consensual unions seem to have been entrenched in Bulgaria for a long time. (Note how high the Bulgarian curve for entry into cohabitation is in Fig. 1.) Anecdotal evidence suggests that there may have been a long-standing pattern where couples who are engaged to be married, move in with one set of their parents and then marry only subsequently, when this fits the family economy and other practical circumstances (observation by Kostova 2007). [This fits well to the quick conversions of consensual to marital unions noted by Koytcheva (2006, Sect. 7.1.1) based on Bulgarian data sets different from the GGS.] In our data, this would be recorded as an entry into a consensual union and a later conversion of the union into a marriage. Figs. 4a and 5 show that after the fall of communism, the conversion activity was scaled down considerably. A consensual union became a much more durable arrangement, fully in agreement with what a description of the SDT would predict. Figure $4 \mathrm{~b}$ extends this painlessly to Hungary, for which, as we remember, we have found a similar drop in the two years right after the turn of the century (Fig. 1). Extensions to the data for Romania and Russia largely show the same pattern for conversion risks (not documented here).

\section{Summary and Reflections}

The union-formation trends that we have revealed in this descriptive study of the four countries in Central and Eastern Europe turn out to have several features in common. Marriage formation has dropped in all the four countries since the fall of communism, and sometimes earlier. Consensual unions have gained ground all the time until the end of the twentieth century, and only in Bulgaria and Hungary does popular interest in consensual-union formation seem to have been reduced somewhat thereafter. In all the four countries, the wind has gone out of the sails of conversions of consensual unions into marriages; so non-marital unions have progressively stayed consensual longer.

Despite all commonalities, it is evident that the SDT, of which we have found some traces, is not a unitary movement that reached all the countries in Central and Eastern Europe roughly at the same time and had the same features throughout, no more than it was in Western Europe. If anything, such a transition did not start simultaneously in all of the four countries, and above all, it began well before the fall of communism and before the societal transition to a market economy got underway around 1990. If we take the distinct drop in marriage formation as a main marker of the start of the SDT as we study it in this article, then a rough estimate would be that it started in Hungary and Bulgaria after the early 1980s and in Russia and Romania half-a-decade and a full decade later, respectively. Such differences should fit with the economic and social developments in the countries, but establishing such a correspondence is a matter of future research. In particular, the special trends in Bulgaria (and possibly Hungary) need further investigation, most likely by bringing in further dimensions in the analysis. We doubt whether it will be enough to continue to study standardized trends in decrement-specific union formation. In any case, our empirical findings have put similar observations made 
by Lesthaeghe and Surkyn (2002); Gerber and Berman (2005); Zakharov (2005), and Spéder $(2004,2005)$ on a firmer empirical ground than before.

As a final reflection on our findings, we want to underline that interpretations should be made with some prudence, for it is possible that the perception of what constitutes a consensual union has varied across countries and has changed over time, and also that reporting inaccuracy may have exaggerated the early growth of entry risks for consensual unions. In brief, the reporting accuracy depends on the respondents' ability to recall and willingness to reveal cohabitational episodes. It is possible that cohabitational episodes that occurred long ago may have been forgotten or suppressed more often than more recent episodes, ${ }^{19}$ and if this is the case, cohabitational behavior at the beginning of our period of observation may have been more extensive than what we can report. If so, then the value change central to the SDT explanation may have been smaller than what meets the eye.

Acknowledgments We have benefitted from very constructive comments from anonymous reviewers, from conversations with colleagues in the Max Planck Institute for Demographic Research, and from impulses provided by Tomas Frejka and Tomas Sobotka. We are grateful to Zsolt Spéder for giving us access to the Hungarian data.

Open Access This article is distributed under the terms of the Creative Commons Attribution Noncommercial License which permits any noncommercial use, distribution, and reproduction in any medium, provided the original author(s) and source are credited.

\section{Appendix: The specification and Interpretation of our Period Coefficients of our Study}

\section{A1. Stable and Uniform Age Profiles}

For a discussion of the mathematical structure of our transition intensities, we note that the quantities plotted in Figs. 1, 2 are maximum-likelihood estimates of parameters $c_{k h}$ and $a_{i h}$ of multiplicative intensity functions that in its most general four-factor representation has the form

$$
\mu_{i j k h}=a_{i h} b_{j h} c_{k h}
$$

Where $i$ is the age group, $j$ is the background group, $k$ is the calendar period, and $h$ is the decrement. ${ }^{20}$ As we have noted, in the present application, the latter stands for the type of union formation, i.e., for entry into a marital or non-marital union, represented by $h=1$ and $h=2$, respectively, say. If we let $A$ stand for the age factor, $B$ for the combination of all the background factors that we mentioned as

\footnotetext{
19 Compare the reflections and findings of Hayford and Morgan 2008, based on similar data for the United States.

${ }^{20}$ Relation (1) is a suitable starting point for a general discussion of the issues that we raise. For reasons that we will make clear as we go along, Figs. 1, 2 have actually been based on simpler specifications, namely $\mu_{i j k h}=a_{i} b_{j} c_{k h}$ for Fig. 1 and $\mu_{i j k h}=a_{i h} b_{j} c_{k h}$ for Fig. 2 . Thus for the diagrams, we use fewer factor interactions (double-subscript parameters) than the general theory allows for.
} 
covariates in Section 2, $C$ for the calendar period, and $D$ for the decrement, ${ }^{21}$ then the above specification of the union-formation intensity can be written symbolically as $\mu=A D+B D+C D$, where a double letter like $A D$ or $C D$ indicates that we include an interaction between the two factors involved ( $A$ and $D$, say, represented in (1) by a double subscript on the $a$ parameter) and a plus sign indicates that an interaction has not been included. We then note that a condition which makes the items in Figs. 1, 2 work as a fair representation of our data, is that for each type $h$ of union entry, the age effect $\left\{a_{i h}\right\}$ is the same in all periods $k$ and for all levels $j$ on the background factor, as is indicated here by the lack of subscripts $k$ and $j$ on the $a$ parameter in (1). In brief, there is a requirement of (i) stability and (ii) uniformity in the age effects for our standardization to work without problem. (Similar requirements must be satisfied for factor $B$.) As we indicated in Section 4, we are of the opinion that the requirements on Factor $A$ cause no essential problem for our empirical analysis.

\section{A2. The Interpretation of Period Coefficients of Our Study as Relative Risks}

We now turn to the issue of the interpretation of the intensity parameters as relative risks. If we had been willing to analyze each decrement separately, then we would be dealing with two individual intensities $\mu_{i j k 1}$ and $\mu_{i j k 2}$, and the very multiplicative specification of each of them, as in (1), would make sure that the parameters $b_{j h}$ and $c_{k h}$ could be interpreted as relative risks, in the usual manner for single-decrement intensities (Hoem 1976). (For the baseline factor $A$, we operate with absolute risks, per 1,000 person-months for instance, and the issue of relative risks does not concern the $a$ parameters.) To secure parameter identification, we would impose side conditions of the type $c_{k_{0}}=1$ and $c_{k_{0} 2}=1$ for a suitable period $k_{0}$, and we would use similar side conditions for the $b$ parameters.

When we want to analyze $\mu_{i j k 1}$ and $\mu_{i j k 2}$ jointly for the purpose of seeing how one of them develops over time (i.e., as a function of $k$ ) relative to the other, things turn out to be a bit more complicated. First, we drop one of the side conditions on each parameter set, and only require that $c_{k_{0}}=1$ for the $c$ parameters, say. For the period factor $C$, we are faced with two types of relative risks, as follows:

(i) For any given type $h$ of union formation, the intensity of union entry for a factor combination $(i, j, k)$, relative to the combination $\left(i, j, k_{0}\right)$, is

$$
\mu_{i j k h} / \mu_{i j k_{0} h}=\frac{a_{i h} b_{j h} c_{k h}}{a_{i h} b_{j h} c_{k_{0} h}}=\frac{c_{k h}}{c_{k_{0} h}} .
$$

Thus in particular for $h=1$,

$$
\mu_{i j k 1} / \mu_{i j k_{0} 1}=c_{k 1}
$$

(because of the side condition $c_{k_{0}}=1$ ) and we see that $c_{k 1}$ is a relative risk in its own right. Furthermore,

$$
\mu_{i j k 2} / \mu_{i j k_{0} 2}=c_{k 2} / c_{k_{0} 2}
$$

$\overline{21}$ Note how we use a mnemotechnical device in the naming of the various factors involved. 
which shows that up to a divisor $c_{k_{0} 2}$, the $c_{k 2}$ are relative risks also. All in all, we have established that the items $c_{k h}$ can essentially be interpreted as relative risks along each curve for every country in Fig. 1. The curves faithfully represent the trend in each competing risk separately. Thus (2.1) and (2.2) show that the form of the trend curves remains independent of the specification of the age and background parameters ( $a$ and $b$ ).

(ii) It remains to compare corresponding points on the two curves for each country, i.e., to compare the curve point for the coordinate $(k, 1)$ with the curve point for $(k, 2)$ for each period $k$. Note that as has essentially been shown before by Hoem and Kostova (2008, end of Appendix),

$$
\mu_{i j k 2} / \mu_{i j k 1}=\frac{a_{i 2} b_{j 2} c_{k 2}}{a_{i 1} b_{j 1} c_{k 1}}=s_{i j} \frac{c_{k 2}}{c_{k 1}} \text { with } s_{i j}=\frac{a_{i 2} b_{j 2}}{a_{i 1} b_{j 1}} .
$$

With the model specification $\mu=A+B+C D, a_{i 2}=a_{i 1}$ for all $i$ and $b_{j 2}=b_{j 1}$ for all $j$, and $s_{i j} \equiv 1$. We have used this model specification to produce all the curves in Fig. 1, and see that we can, therefore, compare directly the trend and level of the risk of entry into cohabitation with the corresponding risk of marriage formation for each country. Our comments in the text proper have been based on this insight.

Our computer program will provide estimates for the $a, b$, and $c$ parameters even if we do not have $s_{i j} \equiv 1$, and the estimates may have some interest in their own right, but we can no longer automatically interpret the $c$ estimates as relative risks and they may easily deviate considerably from those produced by the specification $\mu=A+B+C D$, except in special cases. For instance, the specification $\mu=A D+B+C D$, produces separate age profiles for the two decrements, for it means that we have let $\mu_{i j k h}=a_{i h} b_{j} c_{k h}$, with two separate age profiles $\left\{a_{i 1}\right\}$ and $\left\{a_{i 2}\right\}$, which we have plotted for each country in Fig. 2. We see that for each country, the age profiles of the two entry risks largely coincide except in details (i.e., $a_{i 1} \approx a_{i 2}$ for all $i$ ), i.e., the near-equality of the age profiles need not be such a terrible approximation, though for the details it manifestly is a tall order. So long as we are willing to accept approximations liberally, as one generally does when one practices standardization, the $c$ parameters can therefore still be interpreted as relative risks, because according to (3), $c_{k 2} / c_{k 1}$ largely represents the relative $\operatorname{risk} \mu_{i j k 2} / \mu_{i j k 1}$ as desired. (Remember that $b_{j 1}=b_{j 2}$ for all $\mathrm{j}$ with the given intensity specification, so $b_{j 1}$ and $b_{j 2}$ cancel in $s_{i j}$.) This also shows up in risk-trend diagrams that are much like those in Fig. 1 except for minor details (not displayed here).

We run into trouble if we try to extend these ideas to the specification $\mu=A D+B D+C D$. (When $B$ represents several background factors, each of them is interacted separately with the decrement factor.) For Bulgaria and Romania, the corresponding $c$ plots are much like those in Fig. 1, but for Russia and Hungary the inclusion of the interactions between the decrement and all the background factors produces $c$ plots that really fail to represent properly the trends in union-formation risks. Allowing the background factors to influence the two competing risks differentially (as is the purpose of letting $\mu_{i j k h}=a_{i h} b_{j h} c_{k h}$ with genuinely $h$-dependent $b_{j h}$ ) results in a loss of control over the interpretation of the intensity parameters. We do not know how to interpret our parameters if they 
cannot be taken as relative risks. If a differential impact of the background factors is important, one should probably abstain from a joint analysis of the competing risks and, instead study them separately until one understands better the implications of our formula (3).

\section{References}

Aassve, A., Billari, F. C., \& Spéder, Z. (2004). Family formation during the Hungarian societal transition: Trends in postponement and the impact of policy changes. Presented at the annual meeting of the Population Association of America (PAA).

Andersson, G., \& Philipov, D. (2002). Life-table representations of family dynamics in Sweden, Hungary, and fourteen 14 other FFS countries. A project of descriptions of demographic behavior. Demographic Research, 7(4), 67-144.

Bradatan, C., \& Kulcsar, L.J. (2008). Choosing between marriage and cohabitation: Women's first union patterns in Hungary. Journal of Comparative Family Studies, 39(4) (to appear).

Carlson, E., \& Klinger, A. (1987). Patterns in life: Unmarried couples in Hungary. European Journal of Population, 3, 85-99.

Frejka, T., Sobotka, T., Hoem, J. M., \& Toulemon, L. (Eds.) (2008). Childbearing trends and policies in Europe. Demographic Research, 19 (Special Collection 7), 1-46.

Gerber, T. P., \& Berman, D. (2005). Economic crisis or second demographic transition? trends and correlates of union formation in Russia, 1985-2001. Presented at the annual meeting of the Population Association of America (PAA).

Hayford, S. R., \& Morgan, S. P. (2008). The quality of retrospective data on cohabitation. Demography, 45(1), 129-141.

Hoem, J. M. (1976). The statistical theory of demographic rates: A review of current developments (with discussion). Scandinavian Journal of Statistics, 3(4), 169-185.

Hoem, J. M., \& Kostova, D. (2008). Early traces of the second demographic transition in Bulgaria: A joint analysis of marital and non-marital union formation. Population Studies, 62(3), 1-13.

Hoem, J. M., \& Kreyenfeld, M. (2006). Anticipatory analysis and its alternatives in life-course research. Part 2: Marriage and first birth. Reflexions. Demographic Research, 15(17), 485-498.

Kostova, D. (2007). The rise of cohabitation in Bulgaria: Who are the forerunners of the new family model? Presented at the annual meeting of the Population Association of America (PAA).

Kostova, D. (2008). Union formation in times of social and economic change: evidence from the Bulgarian and Russian GGS. Doctoral dissertation submitted to the University of Rostock. http://intranet.demogr.mpg.de/publications/files/3192_1225298678_1_MPI\%20Kostova.pdf

Koytcheva, E. (2006). Social-demographic differences of fertility and union formation in Bulgaria before and after the start of the societal transition. Doctoral dissertation from the University of Rostock. http://www.demogr.mpg.de/publications/files/ 2318_1153389353_1_Full\%20Text.pdf.

Koytcheva, E., \& Philipov, D. (2008). Bulgaria: Ethnic differentials in rapidly declining fertility. In T. Frejka, T. Sobotka, J. M. Hoem, \& L. Toulemon (Eds.), Childbearing trends and policies in Europe. Demographic Research, 19 (Special Collection 7), 361-402.

Lesthaeghe, R. J., \& Surkyn, J. (2002). New forms of household formation in Central and Eastern Europe: Are they related to newly emerging value orientations? Economic Survey of Europe, 1, 197-216.

Lesthaeghe, R. J., \& van de Kaa, D. J. (1986). Twee demografische transities? In R. J. Lesthegehe \& D. J. van de Kaa (Eds.), Bevolking: groei en krimp (pp. 9-24). Deventer: Van Loghum-Slaterus. Mens en Maatschappij.

Maleva, T. M., \& Sinyavskaya, O. V. (Eds.). (2007). Parents and children, men and women in family and society (in Russian). Moscow: Independent Institute for Social Policy.

Mureşan, C. (2007a). How advanced is Romania in the second demographic transition? Romanian Journal of Population Studies, 1(1-2), 46-60.

Mureşan, C. (2007b). Family dynamics in pre- and post-transition Romania: a life-table description. MPIDR Working Paper 2007-018. 
Mureşan, C., Hărăguş, P.T., Hărăguş, M., \& Schroeder, C. (2008). Romania: Childbearing metamorphosis within a changing context. In T. Frejka, T. Sobotka, J. M. Hoem, \& L. Toulemon (Eds.), Childbearing trends and policies in Europe. Demographic Research, 19 (Special Collection 7), 855-906.

Philipov, D., \& Jasilioniene, A. (2007). Union formation and fertility in Bulgaria and Russia: A life table description of recent trends. MPIDR Working Paper 2007-005.

Sobotka, T. (2008). The diverse faces of the second demographic transition in Europe. In T. Frejka, T. Sobotka, J. M. Hoem, \& L. Toulemon (Eds.), Childbearing trends and policies in Europe. Demographic Research, 19 (Special Collection 7), 171-224.

Spéder, Z. (2001). Turning points of the life course. Concept and design of the Hungarian social and demographic panel survey (in Hungarian). Demográfia, 44(2-3), 305-320. www.dpa.demografia.hu.

Spéder, Z. (2004). Cohabitation and marriage-facts, opinions, trends and transitions. Presented at the annual meeting of the Population Association of America (PAA).

Spéder, Z. (2005). The rise of cohabitation as first union and some neglected factors of recent demographic developments in Hungary. Demográfia, 48, 77-103.

Spéder, Z. (2006). Rudiments of recent fertility decline in Hungary. Demographic Research, 15(8), 253-288.

Spéder, Z., \& Kamarás, F. (2008). Hungary: Secular fertility decline with distinct period fluctuations. In T. Frejka, T. Sobotka, J. M. Hoem, \& L. Toulemon (Eds.), Childbearing trends and policies in Europe. Demographic Research, 19 (Special Collection 7), 599-664.

Thornton, A., \& Philipov, D. (2007). Developmental idealism and family and demographic change in Central and Eastern Europe. European Demographic Research Papers 2007/3, Vienna Institute of Demography. http://www.oeaw.ac.at/vid/download/edrp_3_07.pdf.

Vikat, A., Spéder, Z., Beets, G., Billari, F. C., Bühler, C., Désesquelles, A., et al. (2007). Generations and Gender Survey (GGS). Towards a better understanding of relationships and processes in the life course. Demographic Research, 17(14), 389-440.

Zakharov, S. (2005). Recent trends in first marriage in Russia: Retarded second demographic transition. Presented at the 25th International Population Conference, Tours, France.

Zakharov, S. (2008). Russian Federation: From the first to second demographic transition. In T. Frejka, T. Sobotka, J. M. Hoem, \& L. Toulemon (Eds.), Childbearing trends and policies in Europe. Demographic Research, 19 (Special Collection 7), 907-972. 